\title{
SEJARAH DAN KIPRAH NAHDLATUL ULAMA DI INDONESIA
}

\author{
Fatkhul Mubin \\ fatkhulmubin90@gmail.com
}

\section{A. Latar Belakang}

Keterbelakangan baik secara mental, maupun ekonomi yang dialami bangsa Indonesia, akibat penjajahan maupun akibat kungkungan tradisi, telah menggugah kesadaran kaum terpelajar untuk memperjuangkan martabat bangsa ini, melalui jalan pendidikan dan organisasi. Gerakan yang muncul 1908 tersebut dikenal dengan "Kebangkitan Nasional". Semangat kebangkitan memang terus menyebar ke mana-mana setelah rakyat pribumi sadar terhadap penderitaan dan ketertinggalannya dengan bangsa lain. Sebagai jawabannya, muncullah berbagai organisasi pendidikan dan pembebasan. Kalangan pesantren yang selama ini gigih melawan kolonialisme, merespon kebangkitan nasional tersebut dengan membentuk organisasi pergerakan, seperti Nahdlatul Wathan (Kebangkitan Tanah Air) pada 1916. Kemudian pada tahun 1918 didirikan Taswirul Afkar atau dikenal juga dengan "Nahdlatul Fikri" (kebangkitan pemikiran), sebagai wahana pendidikan sosial politik kaum dan keagamaan kaum santri. Dari situ kemudian didirikan Nahdlatut Tujjar, (pergerakan kaum saudagar). Serikat itu dijadikan basis untuk memperbaiki perekonomian rakyat. Dengan adanya Nahdlatul Tujjar itu, maka Taswirul Afkar, ${ }^{1}$ selain tampil sebagai kelompok studi juga menjadi

\footnotetext{
${ }^{1}$ Saihu, S. (2019). RINTISAN PERADABAN PROFETIK UMAT MANUSIA MELALUI PERISTIWA TURUNNYA ADAM AS KE-DUNIA. Mumtaz: Jurnal Studi Al-Quran dan Keislaman, 3(2), 268-279,

Saihu, S. (2019). Pendidikan Pluralisme Agama: Kajian tentang Integrasi Budaya dan Agama dalam Menyelesaikan Konflik Sosial Kontemporer. Jurnal Indo-Islamika, 9(1), 67-90,

Saihu, S. (2019). IMPLEMENTASI MANAJEMEN BALANCED SCORECARD DI PONDOK PESANTREN JAM'IYYAH ISLAMIYYAH TANGERANG SELATAN. Mumtaz: Jurnal Studi Al-Quran dan Keislaman, 3(1), 1-22.
} 
lembaga pendidikan yang berkembang sangat pesat dan memiliki cabang di beberapa kota. Berangkan komite dan berbagai organisasi yang bersifat embrional, maka setelah itu dirasa perlu untuk membentuk organisasi yang lebih mencakup dan lebih sistematis, untuk mengantisipasi perkembangan zaman. Maka setelah berkordinasi dengan berbagai kyai, akhirnya muncul kesepakatan untuk membentuk organisasi yang bernama Nahdlatul Ulama (Kebangkitan Ulama) pada 16 Rajab 1344 H (31 Januari 1926). Organisasi ini dipimpin oleh K.H. Hasyim Asy'ari sebagai Rais Akbar.

\section{B. Rumusan Masalah}

1. Apa Pengertian Nahdlatul Ulama?

2. Bagaimana Sejarah Berdirinya Nahdlatul Ulama?

3. Bagaimana Biografi Pendiri Nahdlatul Ulama?

4. Lembaga Pendidikan Islam Nahdlatul Ulama?

\section{PEMBAHASAN}

Saihu, S. (2019). KOMUNIKASI PENDIDIK TERHADAP ANAK BERKEBUTUHAN KHUSUS DI SEKOLAH KHUSUS ASY-SYIFA LARANGAN. Andragogi: Jurnal Pendidikan Islam dan Manajemen Pendidikan Islam, 1(3), 418-440.

Saihu, S., \& Marsiti, M. (2019). PENDIDIKAN KARAKTER DALAM UPAYA MENANGKAL RADIKALISME DI SMA NEGERI 3 KOTA DEPOK, JAWA BARAT. Andragogi: Jurnal Pendidikan Islam dan Manajemen Pendidikan Islam, 1(1), 2354. 


\section{A. Pengertian Nahdlatul Ulama}

Nahdlatul Ulama memiliki arti kebangkitan para ulama. Istilah "kebangkitan" itu sendiri pada dasarnya mengandung arti yang lebih aktif jika dibandingkan dengan kata "perkumpulan" atau "perhimpunan". Seperti kita ketahui, para ulama merupakan panutan umat dimana umat akan mengikutinya. Oleh karena itu, dengan kepemimpinan para ulama, diharapkan arah kebangkitan dan kejayaan umat islam serta kaum muslimin akan lebih terlihat jelas dan nyata.

\section{B. Sejarah Berdirinya Nahdlatul Ulama}

Nahdlatul Ulama, disingkat NU, yang artinya kebangkitan ulama. Sebuah organisasi yang didirikan oleh para ulama pada tanggal 31 Januari 1926/16 Rajab 1344 H2 di kampung Kertopaten Surabaya. Untuk memahami NU sebagai organisasi keagamaan secara tepat, belumlah cukup jika hanya melihat dari sudut formal semenjak ia lahir. Sebab jauh sebelum NU lahir dalam bentuk jam'iyyah, ia terlebih dulu ada dan berwujud jama'ah (community) yang terikat kuat oleh aktivitas sosial keagamaan yang mempunyai karakteristik sendiri. $^{2}$

\footnotetext{
2 Fahrudin, Fuad, Agama dan Pendidikan Demokrasi Pengalaman Muhammadiyah dan Nahdlatul Ulama, (Jakarta Pustaka Alvabet 2009).50-

51, Saihu, S. (2019). KONSEP MANUSIA DAN IMPLEMENTASINYA DALAM PERUMUSAN TUJUAN PENDIDIKAN ISLAM MENURUT MURTADHA MUTHAHHARI. Andragogi: Jurnal Pendidikan Islam dan Manajemen Pendidikan Islam, 1(2), 197-217.

Saihu, S., \& Rohman, B. (2019). PEMBENTUKAN KARAKTER MELALUI MODEL PENDIDIKAN TRANSFROMATIFE LEARNING PADA SANTRI DI PONDOK PESANTREN NURUL IKHLAS BALI. Edukasi Islami: Jurnal Pendidikan Islam, 8(02), 435-452.

Saihu, S., \& Taufik, T. (2019). PERLINDUNGAN HUKUM BAGI GURU. Al Amin: Jurnal Kajian Ilmu dan Budaya Islam, 2(2), 105-116.

Saihu, S. (2020). KONSEP PEMBAHARUAN PENDIDIKAN ISLAM MENURUT FAZLURRAHMAN. Andragogi: Jurnal Pendidikan Islam dan Manajemen Pendidikan Islam, 2(1), 82-95.

Saihu, S. (2020). ETIKA MENUNTUT ILMU MENURUT KITAB TA'LIM MUTA’ALIM. Al Amin: Jurnal Kajian Ilmu dan Budaya Islam, 3(1), 99-112.
} 
Latar belakang berdirinya NU berkaitan erat dengan perkembangan pemikiran keagamaan dan politik dunia Islam kala itu. Pada tahun 1924 di Arab Saudi sedang terjadi arus pembaharuan. leh Syarif Husein, Raja Hijaz (Makkah) yang berpaham Sunni ditaklukan oleh Abdul Aziz bin Saud yang beraliran Wahabi. Pada tahun 1924 juga, di Indonesia K.H Wahab Chasbullah mulai memberikan gagasannya pada K.H. Hasyim Asyari untuk perlunya didirikan NU. Sampai dua tahun kemudian pada tahun 1926 baru diizinkan untuk mengumpulkan para ulama untuk mendirikan NU. ${ }^{3}$

Berdirinya Nahdlatul Ulama tak bisa dilepaskan dengan upaya mempertahankan ajaran ahlus sunnah wal jamaah (aswaja). Ajaran ini bersumber dari Al-qur'an, Sunnah, Ijma'(keputusan-keputusan para ulama'sebelumnya) dan Qiyas (kasus-kasus yang ada dalam cerita alQur'an dan Hadits) seperti yang dikutip oleh Marijan dari K.H. Mustofa Bisri ada tiga substansi, yaitu:

1. Dalam bidang-bidang hukum-hukum Islam menganut salah satu ajaran dari empat madzhab (Hanafi, Maliki, Syafi'I, dan Hanbali), yang dalam praktiknya para Kyai NU menganut kuat madzhab Syafi' i.

\footnotetext{
3Sutarmo, Gerakan Sosial Keagamaan Modernis, (Yogyakarta: Suaka Alva 2005).100, Saihu, Aziz, A., Mubin, F., \& Sarnoto, A. Z. (2020). Design of islamic education based on local wisdom (An analysis of social learning theories in forming character through ngejot tradition in bali). International Journal of Advanced Science and Technology, 29(6), 1278-1293.

Ronaldo, R., Zulfikar, A., Saihu, Ismail, \& Wekke, I. S. (2020). International relations of the asia pacific in the age of trump. Journal of Environmental Treatment Techniques, 8(1), 244 246.

Saihu, M. M., \& Aziz, A. (2020). Implementasi Metode Pendidikan Pluralisme Dalam Mata Pelajaran Pendidikan Agama Islam. Belajea; Jurnal Pendidikan Islam, 5(1), 131-150.

Saihu, M. (2019). Urgensi 'Urf dalam Tradisi Male dan Relevansinya dalam Dakwah Islam di Jembrana-Bali. Jurnal Bimas Islam, 12(1), 173-201.

Saihu, S. (2020). The Effect of Using Talking Stick Learning Model on Student Learning Outcomes in Islamic Primary School of Jamiatul Khair, Ciledug Tangerang. Tarbawi: Jurnal Keilmuan Manajemen Pendidikan, 6(01), 61-68. Saihu, S. (2020). Pendidikan sosial yang terkandung dalam Surat At-Taubah Ayat 71-72. Edukasi Islami: Jurnal Pendidikan Islam, 9(01), 127-148.
} 
2. Dalam soal tauhid (ketuhanan), menganut ajaran Imam Abu Hasan AlAsy'ari dan Imam Abu Mansur Al-Maturidzi.

3. Dalam bidang tasawuf, menganut dasar-dasar ajaran Imam Abu Qosim AlJunaidi. Proses konsulidasi faham Sunni berjalan secara evolutif. Pemikiran Sunni dalam bidang teologi bersikap elektik, yaitu memilih salah satu pendapat yang benar. ${ }^{4}$

Hasan Al-Bashri (w. 110 H/728) seorang tokoh Sunni yang terkemuka dalam masalh Qada dan Qadar yang menyangkut soal manusia, memilih pendapat Qodariyah, sedangkan dalam masalah pelaku dosa besar memilih pendapat Murji'ah yang menyatakan bahwa sang pelaku menjadi kufur, hanya imannya yang masih (fasiq). Pemikiran yang dikembangkan oleh Hasan AlBasri inilah yang sebenarnya kemudian direduksi sebagai pemikiran Ahlus sunnah waljama'ah.

\section{Biografi Pendiri Nahdlatul Ulama}

4 Lathiful Khuluk, Fajar Kebangunan Ulama: Biografi KH. Hasyim Asy'ari (Yogyakarta: Lkis Printing Cemerlang).56, Aziz, A., \& Saihu, S. (2019). Interpretasi Humanistik Kebahasaan: Upaya Kontekstualisasi Kaidah Bahasa Arab. Arabiyatuna: Jurnal Bahasa Arab, 3(2), 299-214

Saihu, S. (2019). PENDIDIKAN KARAKTER BERBASIS KEARIFAN LOKAL (STUDI DI JEMBRANA BALI). Edukasi Islami: Jurnal Pendidikan Islam, 8(01), 69-90.

Şahin, C. RELIGIA.

Saihu, S., \& Mailana, A. (2019). Teori pendidikan behavioristik pembentukan karakter masyarakat muslim dalam tradisi Ngejot di Bali. Ta'dibuna: Jurnal Pendidikan Islam, 8(2), 163-176.

Mubin, F. KEADILAN DALAM GENDER: KAJIAN KEPEMIMPINAN WANITA DALAM ISLAM1,

Saihu, M. (2019). Merawat Pluralisme Merawat Indonesia (Potret Pendidikan Pluralisme Agama Di Jembrana-Bali). Deepublish.

Mubin, F. (2019). TAFSIR EMANSIPATORIS: PEMBUMIAN METODOLOGI TAFSIR PEMBEBASAN. Mumtaz: Jurnal Studi Al-Quran dan Keislaman, 3(1), 131-151.

Mubin, F. MODEL-MODEL PEMBELAJARAN BERBASIS MADRASAH DAN KEGIATAN LAIN YANG DIPERLUKAN DI DALAMNYA (FAKTOR PENDUKUNGNYA). 
KH Hasyim Asy'ari dilahirkan pada tanggal 10 April 1875 atau menurut penanggalan arab pada tanggal 24 Dzulqaidah 1287H di Desa Gedang, Kecamatan Diwek, Kabupaten Jombang, Jawa Timur. Beliau wafat pada tanggal 25 Juli 1947 yang kemudian dikebumikan di Tebu Ireng, Jombang.

KH Hasyim Asyari merupakan putra dari pasangan Kyai Asyari dan Halimah, Ayahnya Kyai Ashari merupakan seorang pemimpin Pesantren Keras yang berada di sebelah selatan Jombang.

KH Hasyim Ashari merupakan anak ketiga dari 11 bersaudara. Dari garis keturunan ibunya, KH Hasyim Ashari merupakan keturunan kedelapan dari Jaka Tingkir (Sultan Pajang). dari Ayah dan Ibunya KH Hasyim Ashari mendapat pendidikan dan nilai-nilai dasar Islam yang kokoh.

Sejak anak-anak, bakat kepemimpinan dan kecerdasan KH Hasyim Ashari memang sudah nampak. Di antara teman sepermainannya, ia kerap tampil sebagai pemimpin.

Dalam usia 13 tahun, ia sudah membantu ayahnya mengajar santri-santri yang lebih besar ketimbang dirinya. Usia 15 tahun Hasyim meninggalkan kedua orang tuanya, berkelana memperdalam ilmu dari satu pesantren ke pesantren lain.

Mula-mula ia menjadi santri di Pesantren Wonokoyo, Probolinggo. Kemudian pindah ke Pesantren Langitan, Tuban. Pindah lagi Pesantren Trenggilis, Semarang.

Belum puas dengan berbagai ilmu yang dikecapnya, ia melanjutkan di Pesantren Kademangan, Bangkalan di bawah asuhan Kyai Cholil.

KH Hasyim Asyari belajar dasar-dasar agama dari ayah dan kakeknya, Kyai Utsman yang juga pemimpin Pesantren Nggedang di Jombang. Sejak 
usia 15 tahun, beliau berkelana menimba ilmu di berbagai pesantren, antara lain Pesantren Wonokoyo di Probolinggo, Pesantren Langitan di Tuban, Pesantren Trenggilis di Semarang, Pesantren Kademangan di Bangkalan dan Pesantren Siwalan di Sidoarjo.

Tak lama di sini, Hasyim pindah lagi di Pesantren Siwalan, Sidoarjo. Di pesantren yang diasuh Kyai Ya'qub inilah, agaknya, Hasyim merasa benarbenar menemukan sumber Islam yang diinginkan.

Kyai Ya'qub dikenal sebagai ulama yang berpandangan luas dan alim dalam ilmu agama. Cukup lama lima tahun Hasyim menyerap ilmu di Pesantren Siwalan. Dan rupanya Kyai Ya'qub sendiri menyukai pemuda yang cerdas dan alim itu.

Maka, Hasyim bukan saja mendapat ilmu, melainkan juga istri. Ia, yang baru berumur 21 tahun, dinikahkan dengan Chadidjah, salah satu puteri Kyai Ya'qub.

Tidak lama setelah menikah, Hasyim bersama istrinya berangkat ke Mekkah guna menunaikan ibadah haji. Tujuh bulan di sana, Hasyim kembali ke tanah air, sesudah istri dan anaknya meninggal.

Tahun 1893, ia berangkat lagi ke Tanah Suci. Sejak itulah ia menetap di Mekkah selama 7 tahun dan berguru pada Syaikh Ahmad Khatib Minangkabau, Syaikh Mahfudh At Tarmisi, Syaikh Ahmad Amin Al Aththar, Syaikh Ibrahim Arab, Syaikh Said Yamani, Syaikh Rahmaullah, Syaikh Sholeh Bafadlal, Sayyid Abbas Maliki, Sayyid Alwi bin Ahmad As Saqqaf, dan Sayyid Husein Al Habsyi.

Tahun 1899 pulang ke Tanah Air, Hasyim mengajar di pesanten milik kakeknya, Kyai Usman. Tak lama kemudian ia mendirikan Pesantren 
Tebuireng. Kyai Hasyim bukan saja Kyai ternama, melainkan juga seorang petani dan pedagang yang sukses.

Tanahnya puluhan hektar. Dua hari dalam seminggu, biasanya Kyai Hasyim istirahat tidak mengajar. Saat itulah ia memeriksa sawah-sawahnya.

Kadang juga pergi Surabaya berdagang kuda, besi dan menjual hasil pertaniannya. Dari bertani dan berdagang itulah, Kyai Hasyim menghidupi keluarga dan pesantrennya.

Tahun 1899, Kyai Hasyim membeli sebidang tanah dari seorang dalang di Dukuh Tebuireng. Letaknya kira-kira 200 meter sebelah Barat Pabrik Gula Cukir, pabrik yang telah berdiri sejak tahun 1870 .

Dukuh Tebuireng terletak di arah timur Desa Keras, kurang lebih $1 \mathrm{~km}$. Di sana beliau membangun sebuah bangunan yang terbuat dari bambu (Jawa: tratak) sebagai tempat tinggal.

Dari tratak kecil inilah embrio Pesantren Tebuireng dimulai. Kyai Hasyim mengajar dan salat berjamaah di tratak bagian depan, sedangkan tratak bagian belakang dijadikan tempat tinggal.

Saat itu santrinya berjumlah 8 orang, dan tiga bulan kemudian meningkat menjadi 28 orang. Setelah dua tahun membangun Tebuireng, Kyai Hasyim kembali harus kehilangan istri tercintanya, Nyai Khodijah.

Saat itu perjuangan mereka sudah menampakkan hasil yang menggembirakan. Kyai Hasyim kemudian menikah kembali dengan Nyai Nafiqoh, putri Kyai Ilyas, pengasuh Pesantren Sewulan Madiun.

Dari pernikahan ini Kyai Hasyim dikaruniai 10 anak, yaitu: (1) Hannah, (2) Khoiriyah, (3) Aisyah, (4) Azzah, (5) Abdul Wahid, (6) Abdul Hakim (Abdul 
Kholik), (7) Abdul Karim, (8) Ubaidillah, (9) Mashuroh, (10) Muhammad Yusuf.

Pada akhir dekade 1920an, Nyai Nafiqoh wafat sehingga Kyai Hasyim menikah kembali dengan Nyai Masruroh, putri Kyai Hasan, pengasuh Pondok Pesantren Kapurejo, Pagu, Kediri. Dari pernikahan ini, Kyai Hasyim dikarunia 4 orang putra-putri, yaitu: (1) Abdul Qodir, (2) Fatimah, (3) Khodijah, (4) Muhammad Ya'kub. ${ }^{5}$

\section{Lembaga Pendidikan Islam Nahdlatul Ulama}

Sejarah pergerakan NU sebenarnya adalah sejarah pendidikan nusantara. Pohon organisasi NU sangat rimbun oleh lembaga-lembaga pendidikan seperti pesantren, majelis taklim, diniyyah, madrasah/ sekolah dan perguruan tinggi. Dalam hal pendidikan, NU merupakan salah satu lokomotif pembaharuan pendidikan. Setahun setelah berdirinya, persisnya pada Muktamar NU ke-2 (1927), Muktamirin mengagendakan penggalangan dana secara nasional untuk mendirikan dan membangun madrasah dan sekolah. Pada Muktamar NU ke-3 (1928), elite NU memprakarsai gerakan peduli pendidikan dengan mengajak para Muktamirin untuk mengunjungi pesantren-pesantren besar seperti Tambak Beras yang dipimpin KH. Wahab Chasbullah, Denanyar yang dipimpin oleh KH. Bisri Syamsuri, dan Nganjuk yang dipimpin oleh K. Pathudin Seror Putih.

Pada Muktamar NU ke-4 (1929), panitia Muktamar merespon kecenderungan naiknya kuantitas dan kualitas pendidikan yang mendorong para Muktamirin sepakat untuk membentuk wadah khusus yang menangani bidang pendidikan yang bernama Hoof Bestur Nahdlatul Oelama (HBNO) yang diketuai oleh Ustadz Abdullah Ubaid, waktu itu disebut presiden. Pada 
perkembangan selanjutnya, terbentuklah Lembaga Pendidikan Maarif NU (LPMNU) ada muktamar NU ke 20 (1959) di jakarta. Dari arena Muktamar ke Muktamar, hingga Muktamar NU ke-30 (1999) di Kediri, Lirboyo, Jawa Timur, NU tetap menjadikan sektor pendidikan sebagai mainstream (pemikiran utama). Munas dan Konbes NU tanggal 25-28 Juli 2002 di Pondok Gede Jakarta menghasilkan Taushiyah Pondok Gede Tahun 2002 yang mencoba mempertegas kembali posisi bidang pendidikan untuk menjadi prioritas program NU. Untuk menafsirkan lebih rinci, tak lama setelah itu, tepatnya tanggal 22-25 Agustus 2002 di Kawasan Puncak Batu Malang Jawa Timur, diselenggarakan Rapat Kerja LPMNU dan Musyawarah Kerja Perguruan Tinggi NU. Di forum tersebut, NU kembali mematangkan format, strategi dan guidlines (garis panduan) pengembangan pendidikan di lingkungan NU.

Keberadaan pendidikan di wilayah NU berawal dari keberadaan pesantren. Para kiai pesantren, dahulu kala, ketika pulang dari Timur Tengah ke Indonesia, sebagian besar mendirikan pesantren sebagai institusi pendidikan. Oleh karena pendidikan pesantren, maka keilmuan yang diutamakan adalah keagamaan, khususnya fiqih-hukum-yurisprudensi; dan karena kitab fiqih itu kebanyakan berbahasa Arab, maka untuk memahaminya diperlukan ilmu alat berupa nahwu sharaf, jadi pesantren mesti memiliki perangkat keilmuan nahwu-sharaf. ${ }^{6}$

Pada perkembangan selanjutnya, kira-kira setelah kemerdekaan, terjadi pengembangan model pendidikan di pesantren. Hal ini berawal dari realitas bahwa tidak semua santri yang keluar dari pesantren itu mampu menjadi kiai, sementara mereka tetap membutuhkan ranah pendidikan, akhirnya mereka mendirikan sekolah-sekolah di kampung yang bernama madrasah. Jadi

6 Arief Subhan, Lembaga Pendidikan Islam Indonesia Abad ke 20 (Jakarta: Prenada Media Group 2012).177 
madrasah itu sebenarnya keberlanjutan dari pesantren. Di madrasah, materi keilmuan yang diajarkan pada awalnya adalah sama dengan yang ada di pesantren, bedanya kiai tidak berada dalam lingkup madarasah, tidak seperti pesantren yang memiliki ciri-ciri; ada santri, kitab kuning, kiai, pondokan, dan masjid.

Dalam konteks pendidikan NU, sistem pendidikan pesantren yang telah lama melembaga bagi masyarakat Islam nusantara tidak bisa dilupakan. Keberadaan NU hingga saat ini selalu ditopang oleh pesantren. Dari pesantren basis kekuatan NU dibangun dengan banyak melahirkan para ulama dan kiai, yang kemudian membentuk jamâiyah NU dan berjuang di dalamnya.

Jadi keberadaan pendidikan di lingkungan NU sebelum madrasah- adalah pesantren. Saat ini pendidikan pesantren berada dalam naungan NU, yang penanganannya dipasrahkan pada Lajnah RMI (Lembaga Rabithah MaâTahid Islamiyah), sedangkan pendidikan madrasah berada dalam naungan NU, yang penanganannya diserahkan kepada Lembaga Pendidikan Maarif (LPM).

\section{Kesimpulan}

\section{PENUTUP}

Nahdlatul Ulama memiliki arti kebangkitan para ulama. Istilah "kebangkitan" itu sendiri pada dasarnya mengandung arti yang lebih aktif jika dibandingkan dengan kata "perkumpulan" atau "perhimpunan".

Nahdlatul Ulama, disingkat NU, yang artinya kebangkitan ulama. Sebuah organisasi yang didirikan oleh para ulama pada tanggal 31 Januari 1926/16 Rajab 1344 H2 di kampung Kertopaten Surabaya. Untuk memahami NU sebagai organisasi keagamaan secara tepat, belumlah cukup jika hanya melihat dari sudut formal semenjak ia lahir. Sebab jauh sebelum NU lahir dalam bentuk jam'iyyah, ia terlebih dulu ada dan berwujud jama'ah (community) 
yang terikat kuat oleh aktivitas sosial keagamaan yang mempunyai karakteristik sendiri.

KH Hasyim Asy'ari dilahirkan pada tanggal 10 April 1875 atau menurut penanggalan arab pada tanggal 24 Dzulqaidah 1287H di Desa Gedang, Kecamatan Diwek, Kabupaten Jombang, Jawa Timur. Beliau wafat pada tanggal 25 Juli 1947 yang kemudian dikebumikan di Tebu Ireng, Jombang.

Keberadaan pendidikan di wilayah NU berawal dari keberadaan pesantren. Para kiai pesantren, dahulu kala, ketika pulang dari Timur Tengah ke Indonesia, sebagian besar mendirikan pesantren sebagai institusi pendidikan. Oleh karena pendidikan pesantren, maka keilmuan yang diutamakan adalah keagamaan, khususnya fiqih-hukum-yurisprudensi; dan karena kitab fiqih itu kebanyakan berbahasa Arab, maka untuk memahaminya diperlukan ilmu alat berupa nahwu sharaf, jadi pesantren mesti memiliki perangkat keilmuan nahwu-sharaf.

\section{DAFTAR PUSTAKA}

Aziz, A., \& Saihu, S. (2019). Interpretasi Humanistik Kebahasaan: Upaya Kontekstualisasi Kaidah Bahasa Arab. Arabiyatuna: Jurnal Bahasa Arab, 3(2), 299-214

Fahrudin, Fuad, Agama dan Pendidikan Demokrasi Pengalaman

Muhammadiyah dan Nahdlatul Ulama, Jakarta Pustaka Alvabet 2009

Khuluk Lathiful, Fajar Kebangunan Ulama: Biografi KH. Hasyim Asy’ari

Yogyakarta: Lkis Printing Cemerlang

Mubin, F. (2019). TAFSIR EMANSIPATORIS: PEMBUMIAN METODOLOGI TAFSIR PEMBEBASAN. Mumtaz: Jurnal Studi AlQuran dan Keislaman, 3(1), 131-151.

Mubin, F. KEADILAN DALAM GENDER: KAJIAN KEPEMIMPINAN WANITA DALAM ISLAM1,

Mubin, F. MODEL-MODEL PEMBELAJARAN BERBASIS MADRASAH DAN KEGIATAN LAIN YANG DIPERLUKAN DI DALAMNYA (FAKTOR PENDUKUNGNYA). 
Ronaldo, R., Zulfikar, A., Saihu, Ismail, \& Wekke, I. S. (2020). International relations of the asia pacific in the age of trump. Journal of Environmental Treatment Techniques, 8(1), 244-246.

Şahin, C. RELIGIA.

Saihu, Aziz, A., Mubin, F., \& Sarnoto, A. Z. (2020). Design of islamic education based on local wisdom (An analysis of social learning theories in forming character through ngejot tradition in bali). International Journal of Advanced Science and Technology, 29(6), 1278-1293.

Saihu, M. (2019). Urgensi 'Urf dalam Tradisi Male dan Relevansinya dalam Dakwah Islam di Jembrana-Bali. Jurnal Bimas Islam, 12(1), 173-201.

Saihu, M. (2019). Merawat Pluralisme Merawat Indonesia (Potret Pendidikan Pluralisme Agama Di Jembrana-Bali). Deepublish.

Saihu, M. M., \& Aziz, A. (2020). Implementasi Metode Pendidikan Pluralisme Dalam Mata Pelajaran Pendidikan Agama Islam. Belajea; Jurnal Pendidikan Islam, 5(1), 131-150.

Saihu, S. (2019). IMPLEMENTASI MANAJEMEN BALANCED SCORECARD DI PONDOK PESANTREN JAM'IYYAH ISLAMIYYAH TANGERANG SELATAN. Mumtaz: Jurnal Studi AlQuran dan Keislaman, 3(1), 1-22.

Saihu, S. (2019). KOMUNIKASI PENDIDIK TERHADAP ANAK BERKEBUTUHAN KHUSUS DI SEKOLAH KHUSUS ASY-SYIFA LARANGAN. Andragogi: Jurnal Pendidikan Islam dan Manajemen Pendidikan Islam, 1(3), 418-440.

Saihu, S. (2019). KONSEP MANUSIA DAN IMPLEMENTASINYA DALAM PERUMUSAN TUJUAN PENDIDIKAN ISLAM MENURUT MURTADHA MUTHAHHARI. Andragogi: Jurnal Pendidikan Islam dan Manajemen Pendidikan Islam, 1(2), 197-217.

Saihu, S. (2019). PENDIDIKAN KARAKTER BERBASIS KEARIFAN LOKAL (STUDI DI JEMBRANA BALI). Edukasi Islami: Jurnal Pendidikan Islam, 8(01), 69-90.

Saihu, S. (2019). Pendidikan Pluralisme Agama: Kajian tentang Integrasi Budaya dan Agama dalam Menyelesaikan Konflik Sosial Kontemporer. Jurnal Indo-Islamika, 9(1), 67-90,

Saihu, S. (2019). RINTISAN PERADABAN PROFETIK UMAT MANUSIA MELALUI PERISTIWA TURUNNYA ADAM AS KEDUNIA. Mumtaz: Jurnal Studi Al-Quran dan Keislaman, 3(2), 268279,

Saihu, S. (2020). ETIKA MENUNTUT ILMU MENURUT KITAB TA'LIM MUTA'ALIM. Al Amin: Jurnal Kajian Ilmu dan Budaya Islam, 3(1), 99-112. 
Saihu, S. (2020). KONSEP PEMBAHARUAN PENDIDIKAN ISLAM MENURUT FAZLURRAHMAN. Andragogi: Jurnal Pendidikan Islam dan Manajemen Pendidikan Islam, 2(1), 82-95.

Saihu, S. (2020). Pendidikan sosial yang terkandung dalam Surat At-Taubah Ayat 71-72. Edukasi Islami: Jurnal Pendidikan Islam, 9(01), 127-148.

Saihu, S. (2020). The Effect of Using Talking Stick Learning Model on Student Learning Outcomes in Islamic Primary School of Jamiatul Khair, Ciledug Tangerang. Tarbawi: Jurnal Keilmuan Manajemen Pendidikan, 6(01), 61-68.

Saihu, S., \& Mailana, A. (2019). Teori pendidikan behavioristik pembentukan karakter masyarakat muslim dalam tradisi Ngejot di Bali. Ta'dibuna: Jurnal Pendidikan Islam, 8(2), 163-176.

Saihu, S., \& Marsiti, M. (2019). PENDIDIKAN KARAKTER DALAM UPAYA MENANGKAL RADIKALISME DI SMA NEGERI 3 KOTA DEPOK, JAWA BARAT. Andragogi: Jurnal Pendidikan Islam dan Manajemen Pendidikan Islam, 1(1), 23-54.

Saihu, S., \& Rohman, B. (2019). PEMBENTUKAN KARAKTER MELALUI MODEL PENDIDIKAN TRANSFROMATIFE LEARNING PADA SANTRI DI PONDOK PESANTREN NURUL IKHLAS BALI. Edukasi Islami: Jurnal Pendidikan Islam, 8(02), 435452.

Saihu, S., \& Taufik, T. (2019). PERLINDUNGAN HUKUM BAGI GURU. Al Amin: Jurnal Kajian Ilmu dan Budaya Islam, 2(2), 105-116.

Subhan Arief, Lembaga Pendidikan Islam Indonesia Abad ke 20 Jakarta:

Prenada Media Group 2012

Sutarmo, Gerakan Sosial Keagamaan Modernis, Yogyakarta: Suaka Alva 2005 
